\title{
'||||||||||||||||||||||||||||||||||||||||||||||||||||||||||||||||||||.
}

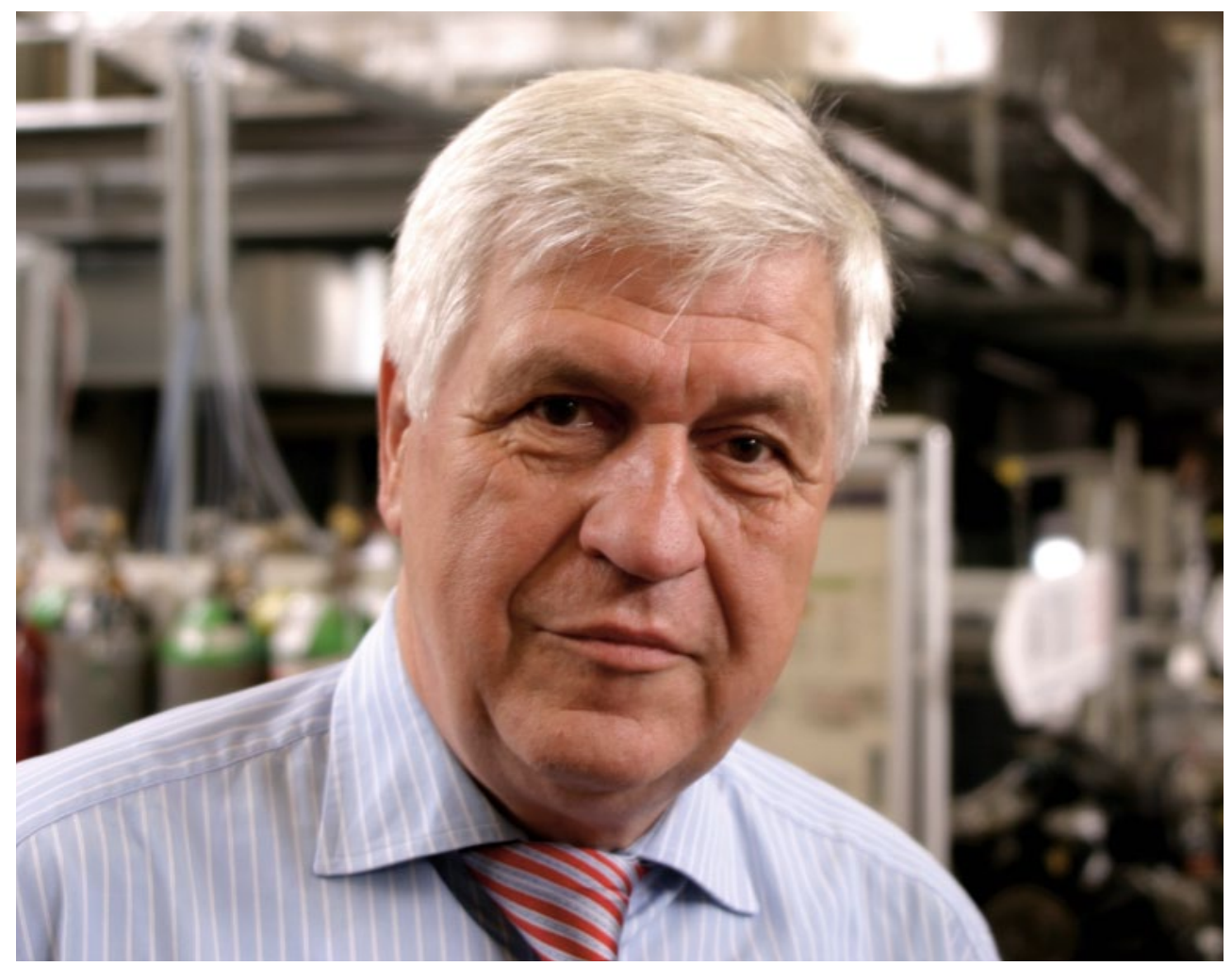

PROF. DR.-ING. DR. H.C. HELMUT TSCHÖKE

Otto-von-Guericke-Universität

Magdeburg und Wissenschaftlicher Leiter der MTZ-Fachtagung Heavy-

Duty-, On- und Off-Highway-Motoren

\section{GEMEINSAMES BEI KLEIN UND GROSS}

Bei Dieselmotoren unterscheiden wir üblicherweise zwischen den kleinen Pkw-Dieselmotoren, den größeren Nutzfahrzeugmotoren und den wirklichen Großmotoren für die Marine und stationäre Anwendungen. So sind auch die Entwicklungsbereiche und Organisationen aufgeteilt und es entstehen getrennte Communities. Vielen Ingenieuren bleibt dadurch der gesamte Überblick verschlossen. Das ist schade und sollte so nicht bleiben.

Alle Motorenentwicklungen müssen dem 4E-Programm folgen: Efficiency, Emissions, Economy, Electrification. Zwar sind die Prioritäten für die verschiedenen Motorgrößen noch unterschiedlich, sie nähern sich aber mit großen Schritten an. Beispiele sind die Stufenaufladung: zuerst beim Nfz-Motor, inzwischen auch im Pkw-Bereich weit verbreitet. Das aufwendig geregelte Luftmanagement mit Aufladung und Abgasrückführung ist beim Pkw wesentlich weiter entwickelt, der NfzMotor schließt auf. Downsizing ist bei größeren Motoren schon längst Praxis, ohne es damals so genannt zu haben. Die Mehrfacheinspritzung wird auch bei größeren Motoren mit bis zu fünf Einspritzungen genutzt. Die bauraum- und gewichtsparende Zylinderlaufflächenbeschichtung ist auch für Nfz-Motoren interessant. Die variable Ventilsteuerung beginnt gerade bei Groß und Klein. Die spezifischen thermodynamischen Belastungen nähern sich an mit Verbrennungsdrücken zwischen 200 bis 240 bar. Die bedarfsabhängige Steuerung der Nebenaggregate ist überall sinnvoll. Die Abgasnachbehandlung ist inzwischen bei allen Motorgrößen weitgehend Standard. Und letztlich ist die Elektrifizierung des Antriebs im Nfz-Bereich längst kein Tabuthema mehr; bei den Marineanwendungen ist sie länger im Einsatz als im Pkw.

Es ist aber müßig zu analysieren, wer jeweils die Nase vorn hatte. Entscheidend ist, dass alle Motoren trotz unterschiedlicher Applikationsanforderungen die gleichen oder ähnliche Technologien benötigen, um das 4E-Programm zu erfüllen. Die Konferenz Heavy-Duty, On-/Off-Highway-Motoren von ATZlive in Nürnberg zeigt dies einmal mehr. Natürlich bleiben Unterschiede, zum Beispiel das Drehzahlniveau und die Lebensdaueranforderungen.

Der Erfahrungsaustausch über Hubraumgrenzen hinweg kann allen Beteiligten nur nützen. Das gilt so ganz nebenbei auch für die Lehre an den Hochschulen. Es ist nur so ein Gefühl, aber ich glaube, unsere Beispiele in den Vorlesungen orientieren sich zu häufig an den vermeintlich attraktiveren Pkw-Motoren. 